\title{
An audit of the insulin-tolerance test in 255 patients with pituitary disease
}

Martin Lange, Ole L Svendsen, Niels E Skakkebæk ${ }^{1}$, Jørn Müller ${ }^{1}$, Anders Juul ${ }^{1}$, Marianne Schmiegelow ${ }^{1}$ and Ulla Feldt-Rasmussen

Department of Endocrinology and ${ }^{1}$ Department of Growth and Reproduction, PE-2132, Rigshospitalet, Blegdamsvej 9, DK-2100 Copenhagen, Denmark

(Correspondence should be addressed to U Feldt-Rasmussen; Email: ufeldt@rh.dk)

\begin{abstract}
Objective: The insulin-tolerance test (ITT) is currently considered to be the gold standard for evaluating adults suspected of GH deficiency (GHD). The aim of this study was to determine factors that may influence nadir blood glucose (BG) when using a mean insulin dose of $0.1 \mathrm{IU} / \mathrm{kg}$ body weight. Furthermore, we wanted to evaluate the safety and GH-related aspects of the ITT.

Design: ITT was performed in 277 patients, of whom 255 (129 females) were eligible for evaluation. Results: Multiple regression analysis, including the whole population, showed that the major determining factors for nadir BG were basal BG and body mass index $(\mathrm{BMI})(P<0.02)$. No serious adverse event was recorded. Sixty-three percent of all patients tested had severe GHD with peak GH response to hypoglycaemia below $7.8 \mathrm{mIU} / \mathrm{l}$. The positive predictive value for IGF-I was 0.82 and the negative predictive value was 0.47 , using a cut-off value corresponding to -2 S.D. GH peak response to hypoglycaemia decreased with increasing numbers of other pituitary hormone deficiencies.

Conclusions: When determining the dose of insulin based on weight, factors like pre-test BG and BMI should also be considered. We propose an algorithm stating that the dose of insulin should be $0.1 \mathrm{IU}$ insulin $/ \mathrm{kg}$ body weight minus 2 IU if pre-test BG is $<4.0 \mathrm{mmol} / \mathrm{l}$ and minus 2 IU if BMI is $<20 \mathrm{~kg} / \mathrm{m}^{2}$ in order to take these factors into account. Our findings furthermore support the concept that the low-dose ITT is a safe test in adults, when performed in experienced hands. It was confirmed that IGF-I is not sufficient when diagnosing GHD in adults, and reliable stimulation tests like ITT are required in the diagnosis.
\end{abstract}

European Journal of Endocrinology $14741-47$

\section{Introduction}

The insulin-tolerance test (ITT) is currently considered to be the gold standard when evaluating adults suspected of growth hormone deficiency (GHD) (1), and is also widely used in the diagnosis of adrenal insufficiency in adults. In some countries, the test is also used in the evaluation of children suspected of these diseases, but because of case reports of deaths in relation to ITT $(2,3)$ this has been abandoned in other countries. The test is also potentially hazardous and unpleasant to the adult patient and has contraindications such as epilepsy and ischaemic coronary and cerebral disease.

The importance of a correctly performed ITT cannot be underestimated since an erroneously performed test may wrongfully result in a lifelong, unnecessary and potentially harmful substitution therapy with both GH and hydrocortisone. Despite this fact and despite the widespread use of the ITT and the fact that the test result is considered comparable between centres (1), controversy regarding test procedures exists. This is especially the case concerning the dose of insulin required to achieve adequate hypoglycaemia (4-9).

In some centres, the test is immediately terminated (by administering i.v. glucose or feeding the patient) once adequate hypoglycaemia has been achieved, while in others i.v. glucose is only administered in the case of adverse events or prolonged hypoglycaemia. Some evidence, however, has implied that the test should not be terminated because of the risk of false negative results (10). An adequate insulin dose is therefore of utmost importance in order to (a) reach sufficient hypoglycaemia and (b) avoid interruption of the test caused by fear of adverse events.

The aim of this study was to determine factors that may influence nadir blood glucose (BG) when using a mean insulin dose of $0.1 \mathrm{IU} / \mathrm{kg}$ body weight in order 
to standardize the process of determining the insulin dose used. Furthermore, we wanted to evaluate safety aspects and the GH-related aspects of the ITT.

\section{Patients and methods}

In the period 1991-1999, 277 ITTs were performed at the Department of Endocrinology, National University Hospital, Copenhagen.

Patient records were retrospectively obtained from 268 patients (nine were not found). Thirteen patients, considered to be insulin insensitive or with diabetes (BG > $7.0 \mathrm{mmol} / \mathrm{l}$, according to WHO (11) and American Diabetes Association criteria) were excluded because they received very high insulin doses and therefore it was considered that they might interfere with the analyses. Thus, 255 patients were eligible for evaluation of the ITT procedure. In most of the tests where indication for performing ITT was evaluation of the pituitary-adrenal axis, $\mathrm{GH}$ was nevertheless measured, and these patients were included in the evaluation of the $\mathrm{GH}$-insulin-like growth factor-I (IGF-I) axis. In seven patients evaluated for adrenal deficiency only, GH was, however, not measured, and in 20 patients IGF-I was not measured in relation to the ITT. Two hundred and thirty patients were therefore eligible for evaluation of the GH-IGF-I axis. None of the patients had, according to their records, factors such as liver disease or malnutrition that might have affected IGF-I levels. Cortisol levels were obtained from 229 patients. Body mass index (BMI) was available in 241 patients. Of the patients tested for GHD, 69 had childhood onset (CO) GHD.

Table 1 Patient characteristics expressed in median (range), original diagnosis and indication for performing ITT in 255 patients.

\begin{tabular}{cl}
\hline Patient characteristics & \\
Females/males & $129 / 126$ \\
Age (years) & $35(14-80)$ \\
Height $(\mathrm{m})$ & $169(141-198)$ \\
Weight $(\mathrm{kg})$ & $75(41-136)$ \\
BMI $\left(\mathrm{kg} / \mathrm{m}^{2}\right)$ & $26(15-56)$ \\
Original diagnosis & \\
Pituitary adenoma & $44.5 \%$ \\
Craniopharyngioma & $9 \%$ \\
Other intracranial neoplasm & \\
$\quad+$ radiation & $17.5 \%$ \\
$\quad-$ radiation & $0.5 \%$ \\
Idiopathic pituitary deficiency & $10 \%$ \\
Other & $18.5 \%$ \\
Evaluation of GH status & \\
Evaluation of pituitary-adrenal axis & $11.6 \%$ \\
A combination of both & $20.9 \%$ \\
Others & $0.1 \%$
\end{tabular}

The characteristics of the patients, original diagnosis and the indications for performing ITT are shown in Table 1.

\section{ITT procedure}

The same technician in co-operation with an experienced physician performed all the ITTs. The patients had fasted from $2300 \mathrm{~h}$ on the day before the test. If the patients were on hydrocortisone substitution therapy, the last dose was at least $12 \mathrm{~h}$ before the test. All tests were performed at $0900 \mathrm{~h}$. Intravenous access was obtained in an antecubital vein and blood samples were taken at $-15,0,15,30,45,60,75$ and $90 \mathrm{~min}$ for $\mathrm{GH}$, cortisol and $\mathrm{BG}$ analyses. For immediate BG measurements, a photometric B-Glucose analyser from HemoCue was used at the same timeintervals. At 0 min, i.v. insulin (actrapid; Novo Nordisk, Gentofte, Danmark) was administered. The insulin dose was determined from body weight at the relatively low dose of $0.1 \mathrm{IU} / \mathrm{kg}$. The dose was adjusted if the patient was considered to be insulin resistant or likely to be very insulin sensitive. These adjustments were based on the experience of the technician and physician rather than on measurable facts. The tests were not routinely terminated by administering i.v. glucose once adequate hypoglycaemia was reached except in case of adverse events or prolonged hypoglycaemia. After $90 \mathrm{~min}$ the patients were given a meal after which they left the Department.

Permission to perform this audit was obtained from the local ethical committee and registration board.

\section{Methods}

BG was measured using full blood in a HemoCue B-Glucose analyzer (precision: S.D. $\leq 0.3 \mathrm{mmol} / \mathrm{l}$ ).

Plasma cortisol was analysed using high pressure liquid chromatography (HPLC) from 1991 to 1995, a fluorescence immunometric assay (Delfia, Wallac, Finland) from 1995 to 1997, a fluorometric assay (autoDelfia, Wallac) from 1997 and another fluorometric assay from 1999 to the present day. To ensure the stability of the analysis, the Delfia assays were calibrated against the HPLC at regular intervals.

Plasma GH was measured using a polyclonal radioimmunoassay (Pharmacia hGH RIA; Pharmacia, Stockholm, Sweden) from 1991-1994, a fluorescence immunometric assay (Delfia, Wallac) from 1994 to 1997 and another fluorescence immunoassay (autoDelfia, Wallac) from 1997 to the present day. To ensure the stability of the analysis, the same standard (WHO 1st IRP 80/505) was used at regular intervals throughout the period. 


\section{Statistics}

The test values examined (height, weight, BMI, insulin dose, insulin dose/kg body weight, basal blood glucose (BBG), nadir blood glucose (NBG), IGF standard deviation score (SDS), and cortisol) followed a normal distribution. GH peak and age did not follow a normal distribution. Pearson and Spearman analyses were used for correlations involving normally distributed values and non-normally distributed values respectively, and considered significant if $P$ was $<0.05$. Normally distributed values that correlated significantly to the dependent factor (NBG) were entered in a stepwise multiple regression analysis.

In order to compare IGF-I between patients independent of age and gender, the values were transformed to SDS based on a previously published reference population (12). An unpaired $t$-test was performed when comparing groups of normally distributed values and Mann-Whitney U test for those values not normally distributed.

The formulas used for sensitivity, specificity, positive predictive value and negative predictive value were: true positive $(\mathrm{TP}) / \mathrm{TP}+$ false negative $(\mathrm{FN})$, true negative $(\mathrm{TN}) /$ false positive $(\mathrm{FP})+\mathrm{TN}, \mathrm{TP} / \mathrm{TP}+\mathrm{FP}$ and TN/FN + TN respectively. When calculating sensitivity, specificity and positive and negative predictive value, IGF-I SDS was used so as to be able to compare the patients independent of age and gender. Values below -2 s.D. were considered abnormal.

\section{Results}

The results of the ITTs are shown in Table 2.

NBG correlated significantly with BBG $(r=0.40)$, insulin dose/kg body weight $(r=0.23)$ and BMI $(r=$ 0.24) when all ITTs were considered $(P<0.001)$. The correlation between NBG and insulin dose/kg body weight was positive, i.e. the higher the insulin dose the higher the NBG. Two hundred and forty one patients entered a multiple regression analysis showing that independent factors for determining NBG were BBG $(\beta=0.38, P<0.00001)$ and BMI $(\beta=0.23$, $P=0.02$ ); $\mathrm{SEE} \%$ (standard error of estimate) $=12 \%$, $r^{2}=0.2$. When analysing patients who received an insulin dose of $0.09-0.11 \mathrm{IU} / \mathrm{kg}$ body weight $(n=$ 122), the only significant correlations were between $\mathrm{NBG}$ and BBG $(r=0.38, P=0.0000001)$.

Table 2 Outcome of ITT in 255 patients suspected for GH and/or adrenal deficiency.

\begin{tabular}{ll}
\hline Insulin dose & $0.11(0.075-0.18) \mathrm{IU} / \mathrm{kg}$ \\
BBG & $4.1(2.5-5.9) \mathrm{mmol} / \mathrm{I}$ \\
NBG & $1.3(0.2-2.9) \mathrm{mmol} / \mathrm{I}$ \\
Target NBG achieved & $98 \%$ \\
Minor adverse events & $5 \%$ \\
Serious adverse event/aborted tests & $0 \%$ \\
\hline
\end{tabular}

As shown in Fig. 1, NBG, BBG, GH peak, IGF SDS and basal and peak cortisol decreased significantly with increasing numbers of additional pituitary deficiencies.

The mean NBG and insulin dose in the patients who experienced adverse events were comparable with those of the total population ( $1.2 \mathrm{vs} 1.3 \mathrm{mmol} / \mathrm{l}$ and $0.104 \mathrm{vs}$ $0.105 \mathrm{IU} / \mathrm{kg}$ body weight respectively). The change in BG, however, was 3.4 vs $2.8 \mathrm{mmol} / \mathrm{l}$ in the total population.

Only 31 patients received an insulin dose exceeding $0.12 \mathrm{IU} / \mathrm{kg}$ body weight. These patients were characterized by high BMI (mean $29.5 \mathrm{~kg} / \mathrm{m}^{2}$ ) and BBG (mean $4.5 \mathrm{mmol} / \mathrm{l}$ ) compared with the total population.

Sixty-three percent of all patients tested for GHD had a GH response to ITT below $7.8 \mathrm{mIU} / \mathrm{l}(3 \mu \mathrm{g} / \mathrm{l})$ with no difference between adult onset (AO) and CO GHD. Twenty-one percent of all tested patients with decreased GH response to ITT had no other hormone deficiencies, i.e. isolated GHD.

The GH peak response correlated significantly with the IGF-I SDS $(r=0.41, P<0.0001)$. This correlation was improved when evaluating only CO GHD $(r=0.59, P<0.0001)$. The impact of BMI and $\mathrm{CO}$ vs $\mathrm{AO} \mathrm{GHD}$ on the relationship between $\mathrm{GH}$ peak and IGF SDS is shown in Fig. 2.

Using -2 S.D. as cut-off, the positive predictive value of IGF-I to predict a pathological peak GH response $(<7.8 \mathrm{mIU} / \mathrm{l})$ was 0.82 and the negative predictive value was 0.47 . Sensitivity and specificity were 0.44 and 0.83 respectively. Omitting patients with BMI $>25 \mathrm{~kg} / \mathrm{m}^{2} \quad(n=138)$, sensitivity, specificity, positive and negative predictive values for IGF-I in relation to outcome of GH testing were $0.40,0.94,0.94$ and 0.40 respectively.

Cortisol was measured during ITT in 229 patients. Of these, 135 had a peak cortisol response to ITT below $500 \mathrm{nmol} / \mathrm{l}$.

\section{Discussion}

\section{ITT}

ITT is still considered to be the gold standard when evaluating patients suspected of $\mathrm{GH}$ and/or adrenal deficiency (1). The potential risks and possible discomfort for the patients are, however, some of the concerns involved when using ITT. Reports of deaths or serious adverse events connected with ITT exist in the literature. These events, however, were probably caused by i.v. dextrose, causing severe hyperglycaemia, rather than the initial insulin-induced hypoglycaemia $(2,3)$. Furthermore, the test has contra-indications $(4,5)$. Alternatives to ITT have therefore been evaluated (13-16). The ITT is, however, still the test of choice in many centres if the patients have no contra-indications (1).

Correct diagnosis when evaluating adult patients for GHD is imperative. A false positive diagnosis will wrongfully render the patient subject to an expensive 


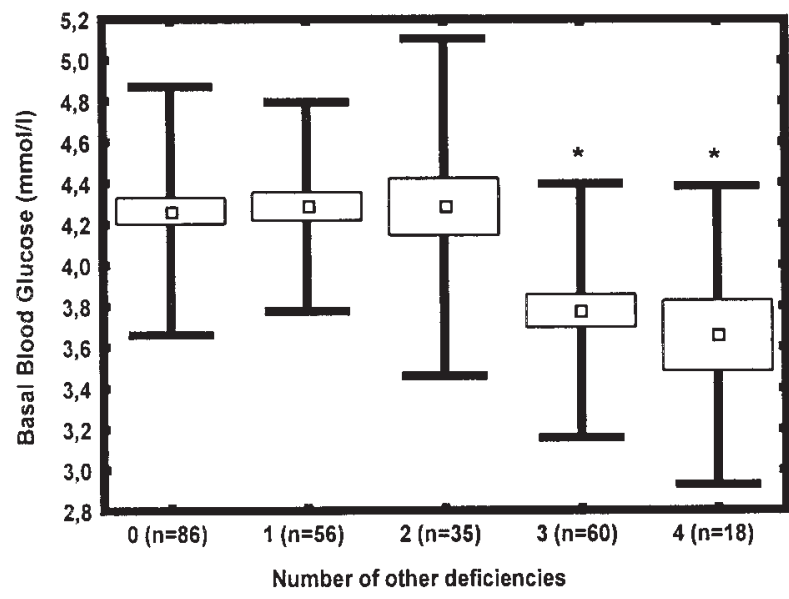

C

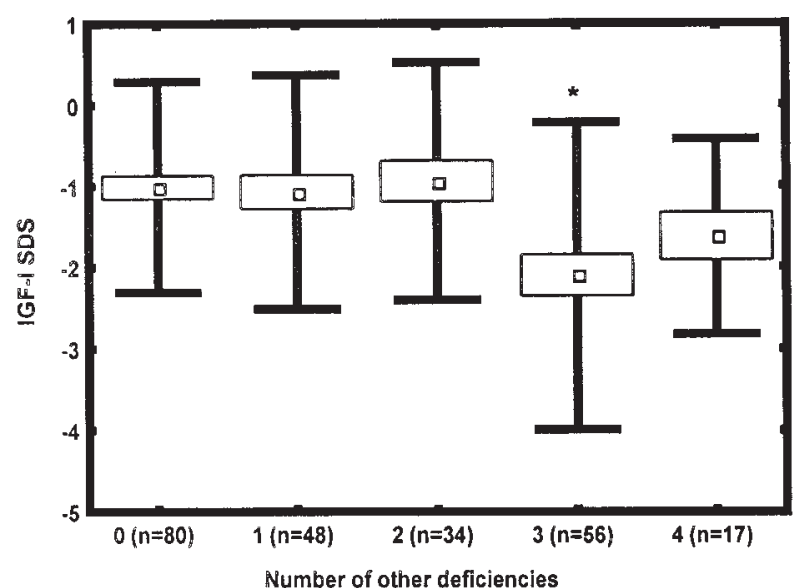

e

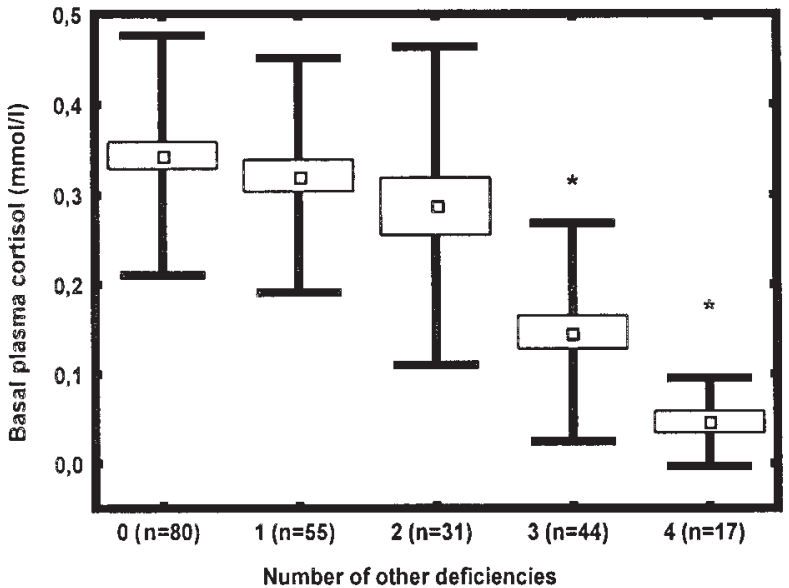

b

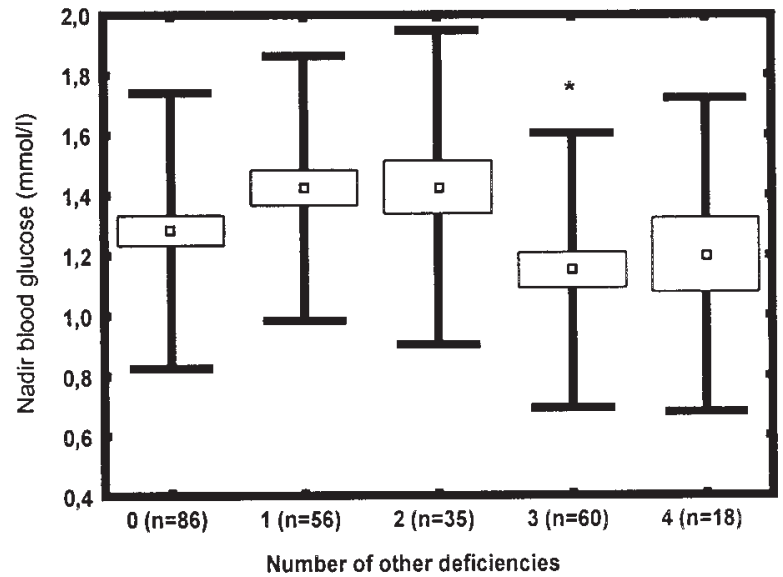

d

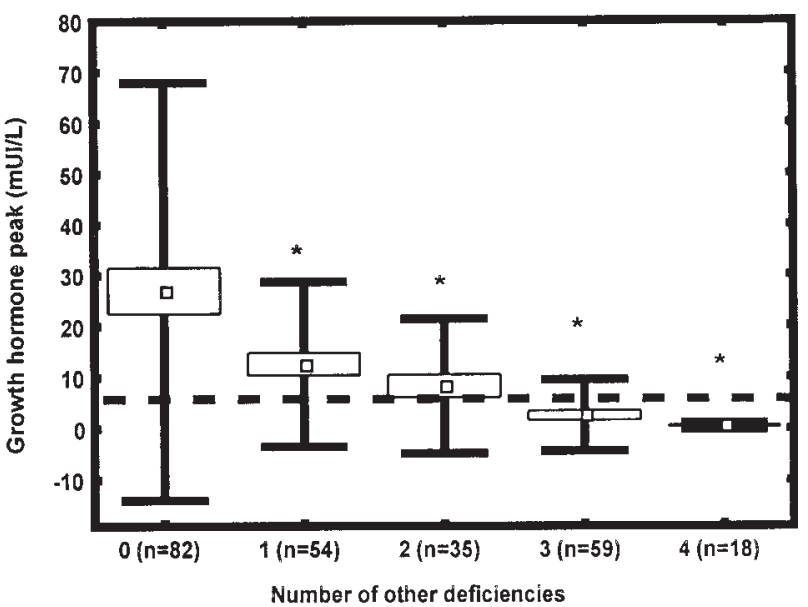

f

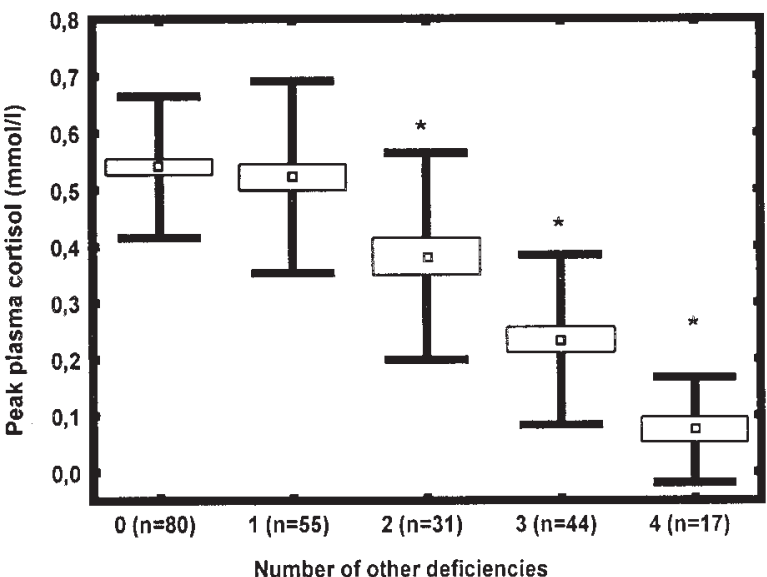

Figure 1 (a) BBG, (b) NBG, (c) IGF-I SDS, (d) GH peak, (e) basal cortisol and (f) peak cortisol versus the number of pituitary deficiencies other than GHD (corticotrophin, thyrotrophin, luteinizing hormone/follicle-stimulating hormone or anti-diuretic hormone $(A D H))$. The number of patients is stated in each case. In (d) the cut-off for $\mathrm{GH}$ of $7.8 \mathrm{mlU} / \mathrm{l}$ is shown. Small boxes represent the mean, large boxes represent S.E. and bars represent S.D. ${ }^{*} P<0.05$ compared with $0,1,2,3$ and 4 other deficiencies (unpaired $t$-test). 

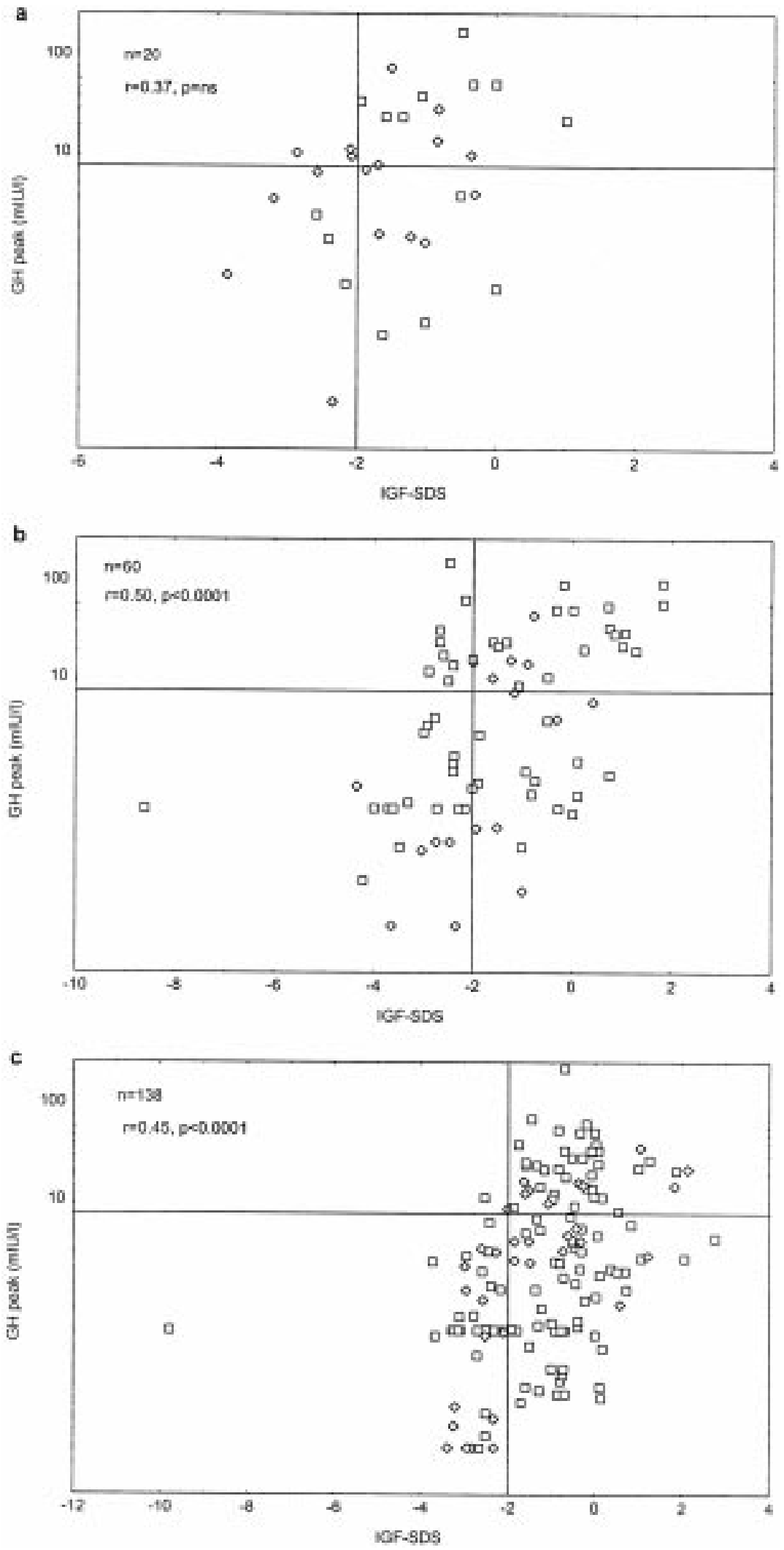

Figure 2 GH peak vs IGF-I SDS divided into (a) $\mathrm{BMI}<20 \mathrm{~kg} / \mathrm{m}^{2}$, (b) BMI $20-25 \mathrm{~kg} / \mathrm{m}^{2}$ and (c) BMI $\geq 25 \mathrm{~kg} / \mathrm{m}^{2}$. A cut-off for $\mathrm{GH}$ of $7.8 \mathrm{mlU} / \mathrm{l}$ is shown by the horizontal lines. IGF SDS -2 is shown by the vertical lines. The number of patients is shown in each case. Twelve patients were excluded since BMI data were not available. AO GHD ( $\square)$ and $\mathrm{CO} \mathrm{GDH}(\diamond)$. 
lifelong treatment, whereas a false negative diagnosis will deprive the patient of treatment for a disease associated with risk of increased morbidity and mortality (17).

Some centres have introduced the policy that when BG reaches a certain level the test is interrupted by i.v. glucose and/or a meal. Donaubauer et al. (10) have, however, raised a concern about interrupting a test by showing the impact on the test results $(\mathrm{GH}$ and cortisol response) of i.v. glucose (either given routinely or because of adverse events). Three normal subjects had two ITTs performed, one during which the test was interrupted by i.v. glucose, and one during which BG was allowed to recover spontaneously. Even with these small numbers, they demonstrated a risk of falsely diagnosing GHD and/or adrenal insufficiency when the test is interrupted (10).

In the literature, a range of $0.5-3.0 \mathrm{IU} / \mathrm{kg}$ body weight has been recommended/used depending on factors such as known insulin insensitivity, acromegaly (higher doses) and pituitary/adrenal deficiency (lower doses) $(4-7,18)$. In one centre, BMI was included as an additional determinant of insulin dose (19).

In our study, a relatively low mean insulin dose of 0.105 (range $0.075-0.18$ ) IU/kg body weight was used, in an attempt to reach an appropriate NBG. A median NBG of $1.30(0.2-2.9) \mathrm{mmol} / \mathrm{l}$ suggested that this relatively low dose might even be too high in some patients, despite the low number of minor adverse events and the absence of serious adverse events. With this dose $98 \%$ of the patients, however, reached adequate hypoglycaemia.

In order to obtain a more accurate estimate of an adjusted insulin dose we evaluated factors that may affect NBG. Surprisingly, factors like gender, adrenal deficiency and body weight did not correlate significantly with NBG. These factors may, on the other hand, be reflected in the level of BBG and BMI as suggested by our observations, and BBG and BMI and, to some extent age, should therefore be considered when calculating insulin dose, using $0.1 \mathrm{IU} / \mathrm{kg}$ body weight as an a priori dose.

A range in the dose of insulin of 0.075 to $0.18 \mathrm{IU} / \mathrm{kg}$ body weight, as observed in the present audit, is wide though, and it may be argued that the above evaluation does not reflect the correct situation in a broad sense. However, in the 122 patients who received an insulin dose of $0.09-0.11 \mathrm{IU} / \mathrm{kg}$ body weight, BBG again correlated highly significantly with NBG, stressing its importance.

As shown in Fig. 1, we found a significantly lower BBG in patients with three or four additional pituitary deficiencies compared with the other groups. BBG may thus reflect the degree of hypopituitarism. The range is still wide and an insulin dose adjustment should therefore be based more on BBG than merely on the diagnosis of hypopituitarism.

On the basis of the identification of BBG and BMI as determinants for $\mathrm{NBG}$, we have recently tried to take these factors into account in a subgroup of 35 consecutive patients. In all 35 patients the standard insulin dose was $0.1 \mathrm{IU} / \mathrm{kg}$ body weight. If the patients had a BBG $<4.0 \mathrm{mmol} / \mathrm{l}$ (arbitrarily chosen), $2 \mathrm{IU}$ insulin (also arbitrarily chosen) were subtracted from the calculated weight-based dose $(n=20)$. If the patient had a body fat content below $25 \%$ (as determined by dexamethasone) or a BMI $<20 \mathrm{~kg} / \mathrm{m}^{2}$, another $2 \mathrm{IU}$ were subtracted $(n=2)$. Thus, the algorithm derived was: $0.1 \mathrm{IU}$ insulin/kg body weight minus $2 \mathrm{IU}$ (if $\mathrm{BBG}$ is $<4.0 \mathrm{mmol} / \mathrm{l}$ ) and minus $2 \mathrm{IU}$ (if BMI is $<20 \mathrm{~kg} / \mathrm{m}^{2}$ ). Using this algorithm, the patients reached an NBG between 1.0 and $1.9 \mathrm{mmol} / \mathrm{l}$. No side-effects were observed.

A similar algorithm for patients with high BBG and BMI (implying insulin resistance) has not yet been introduced but is needed in patients considered to be insulin resistant such as patients with Cushing's disease or active acromegaly (the latter have the test performed in order to diagnose adrenal deficiency).

Of 255 performed tests in the present study, i.v. glucose was administered in 12 tests $(5 \%)$ because of the discomfort of the patient. No serious adverse events (loss of consciousness, seizures, cardiovascular incidents or death) were observed. In 250 out of 255 tests $(98 \%)$, the target NBG was achieved. This suggests, in accordance with others, that the ITT is a safe test when performed in experienced hands (6).

\section{GH deficiency}

A large proportion (37\%) of the patients tested for GHD did in fact have a sufficient GH response to ITT. The number corresponded well with the findings of others $(20,21)$. Also in accordance with others, we found that $21 \%$ of our patients had isolated GHD (22), the majority of whom had CO GHD. The diagnosis of isolated GHD was, in all of these patients, confirmed by an additional stimulation test with either arginine or ITT.

IGF-I values correlated poorly with peak GH. This correlation was greatly improved when evaluating only CO GHD $(r=0.6)$. These findings are in accordance with others, when considering the relationship between peak GH during ITT and IGF-I (23-25). Obesity impairs the $\mathrm{GH}$ response when trying to stimulate the GH axis. This fact is illustrated in Fig. 2, showing that most patients with a low $\mathrm{GH}$ peak and normal IGF-I SDS were obese. Consequently, removing the obese patients from the evaluation improved sensitivity, but this was at the expense of specificity.

As may be expected, the GH peak to hypoglycaemia decreased with increasing numbers of other hormone deficiencies. Our numbers were too small, but our findings indicated that three or four additional pituitary deficiencies may be diagnostic for GHD. Interestingly, IGF-I SDS did not correlate with the number of pituitary hormone deficiencies. Further investigation with greater 
numbers may show that an ITT is unnecessary in these patients since the diagnosis has already been made.

We conclude that when determining insulin dose based on weight, factors such as pre-test BG and BMI should be considered to avoid both too high and too low NBG. We have proposed an algorithm stating that the insulin dose should be $0.1 \mathrm{IU}$ insulin $/ \mathrm{kg}$ body weight minus $2 \mathrm{IU}$ if pre-test $\mathrm{BG}$ is $<4.0 \mathrm{mmol} / \mathrm{l}$ and minus $2 \mathrm{IU}$ if $\mathrm{BMI}$ is $<20 \mathrm{~kg} / \mathrm{m}^{2}$ in order to take these factors into account. In accordance with others (6), we furthermore conclude that our findings support the concept that low-dose ITT is a safe test in adults, when performed in experienced hands. As expected, the $\mathrm{GH}$ peak decreased with increasing numbers of other pituitary hormone deficiencies. Future studies may show that this may be diagnostic for GHD. IGF-I correlates better with peak $\mathrm{GH}$ in $\mathrm{CO}$ GHD than in AO GHD. IGF-I is, however, not sufficient for the diagnosis of GHD but is useful in the screening for GHD. The use of IGF-I is best in CO GHD and non-obese patients. Reliable stimulation tests like ITT are still required for making the diagnosis.

\section{Acknowledgements}

The invaluable technical assistance of technician Lisbeth Kirkegaard is highly appreciated. This study was supported by grants from the Danish Medical Research Council.

\section{References}

1 Consensus guidelines for the diagnosis and treatment of adults with growth hormone deficiency: summary statement of the Growth Hormone Research Society Workshop on Adult Growth Hormone Deficiency. Journal of Clinical Endocrinology and Metabolism 199883 379-381.

2 Burke CW. The pituitary megatest: outdated? Clinical Endocrinology $199236133-134$.

3 Shah A, Stanhope R \& Matthew D. Hazards of pharmacological tests of growth hormone secretion in childhood. British Medical Journal 1992304 173-174.

4 Thorner M, Vance ML, Laws ER, Horvath E \& Kovacs K. The anterior pituitary. In Williams Textbook of Endocrinology, pp 280. Eds JD Wilson, DW Foster, HM Kronenberg \& LP Reed, 1998. USA: WB Saunders Co.

5 Daniels GH \& Martin JB. Neuroendocrine regulation and diseases of the anterior pituitary and hypothalamus. In Harrison's Principles of Internal Medicine, pp 1674. Eds JD Wilson, E Braunwals, KJ Isselbacher, RG Petersdorf, JB Martin \& AS Fausci et al., 1991. USA: McGraw-Hill Inc.

6 Jones SL, Trainer PJ, Perry L, Wass JA, Bessser GM \& Grossman A. An audit of the insulin tolerance test in adult subjects in an acute investigation unit over one year. Clinical Endocrinology 199441 $123-128$.

7 Fisker S, Jorgensen JO, Orskov H \& Christiansen JS. L-Arginine and insulin-tolerance tests in the diagnosis of adult growth hormone deficiency: influence of confounding factors. Clinical Endocrinology $1998 \mathbf{4 8} 109-115$.

8 Lissett CA, Thompson EG, Rahim A, Brennan BM \& Shalet SM. How many tests are required to diagnose growth hormone $(\mathrm{GH})$ deficiency in adults? Clinical Endocrinology 199951 551-557.
9 Pfeifer M, Verhovec R, Zizek B, Prezelj J, Poredos P \& Clayton RN. Growth hormone $(\mathrm{GH})$ treatment reverses early atherosclerotic changes in GH-deficient adults. Journal of Clinical Endocrinology and Metabolism $1999 \mathbf{8 4} 453-457$.

10 Donaubauer J, Kratzsch J, Willgerodt H, Kiess W, Nowak T \& Keller E. Importance of hypoglycaemic symptoms in insulin tolerance test. Growth Hormone and IGF Research 200010172.

11 Alberti KG \& Zimmet PZ. Definition, diagnosis and classification of diabetes mellitus and its complications. Part 1: diagnosis and classification of diabetes mellitus; provisional report of a WHO consultation. Diabetic Medicine 199815 539-553.

12 Juul A, Bang P, Hertel NT, Main K, Dalgaard P, Jørgensen K et al. Serum insulin-like growth factor-I in 1030 healthy children, adolescents and adults: relation to age, sex, state of puberty, testicular size and body mass index. Journal of Clinical Endocrinology and Metabolism $1994 \mathbf{7 8} 744-752$.

13 Longobardi S, Merola B, Pivonello R, Di Relle F, Di Somma C, Coalo A et al. Reevaluation of growth hormone (GH) secretion in 69 adults diagnosed as GH-deficient patients during childhood. Journal of Clinical Endocrinology and Metabolism $1996 \mathbf{8 1}$ 1244-1355.

14 Andersen M, Hansen TB, Stoving RK, Bertelsen J, Hangaard J. Petersen PH et al. The pyridostigmine-growth-hormone-releasinghormone test in adults. The reference interval and a comparison with the insulin tolerance test. Endocrinology and Metabolism 1996 3 197-206.

15 Ghigo E, Aimaretti G, Gianotti L, Bellone J, Arvat E \& Camanni F. New approach to the diagnosis of growth hormone deficiency in adults. European Journal of Endocrinology $1996134352-356$.

16 Aimaretti G, Baffoni C, DiVito L, Bellone S, Grottoli S, Maccario M et al. Comparisons among old and new provocative tests of $\mathrm{GH}$ secretion in 178 normal adults. European Journal of Endocrinology $2000142347-352$.

17 Rosén T \& Bengtsson BÅ. Premature mortality due to cardiovascular disease in hypopituitarism. Lancet 1990336 285-288.

18 Pfeifer M, Kanc K, Verhovec R \& Kocijancic A. Reproducibility of the insulin tolerance test (ITT) for assessment of growth hormone and cortisol secretion in normal and hypopituitary adult men. Clinical Endocrinology 200154 17-22.

19 Dullaart RP, Pasterkamp SH, Beentjes JA \& Sluiter WJ. Evaluation of adrenal function in patients with hypothalamic and pituitary disorders: comparison of serum cortisol, urinary free cortisol and the human-corticotrophin releasing hormone test with the insulin tolerance test. Clinical Endocrinology 199950 465-471.

20 Nicolson A, Toogood AA, Rahim A \& Shalet SM. The prevalence of severe growth hormone deficiency in adults who received growth hormone replacement in childhood. Clinical Endocrinology 199644 311-316.

21 Toogood AA \& Shalet SM. Diagnosis of severe growth hormone (GH) deficiency in young adults who received GH replacement therapy during childhood. Acta Paediatrica 1997423 (Suppl.) $117-120$.

22 Toogood AA, Beardwell CG \& Shalet SM. The severity of growth hormone deficiency in adults with pituitary disease is related to the degree of hypopituitarism. Clinical Endocrinology 199441 $511-516$.

23 Aimaretti G, Corneli G, Razzore P, Bellone S, Baffoni C, Bellone J et al. Usefulness of IGF-I assay for the diagnosis of GH deficiency in adults. Journal of Endocrinological Investigation $1998 \mathbf{2 1}$ 506-511.

24 Hoffman DM, O'Sullivan AJ, Baxter RC \& Ho KK. Diagnosis of growth-hormone deficiency in adults. Lancet $1994 \mathbf{3 4 3}$ 1064-1068.

25 Svensson J, Johannsson G \& Bengtsson BA. Insulin-like growth factor-I in growth hormone-deficient adults: relationship to population-based normal values, body composition and insulin tolerance test. Clinical Endocrinology 199746 579-586.

Received 11 January 2002

Accepted 20 March 2002 